\title{
LONG-TERM EFFiCACY AND SAFETy OF OnCE-DAILy NEVIRAPINE IN Combination with Tenofovir and Emtricitabine in the Treatment of HIV-INFECTED PATIENTS: A 72-week Prospective Multicenter Study (TENOR-Trial)
}

\author{
T. Weberschock ${ }^{1}$, P. Gholam ${ }^{1}$, E. Hueter ${ }^{1}$, K. Flux ${ }^{1}$, SWS Study Centers ${ }^{2}$, M. Hartmann ${ }^{1}$ \\ ${ }^{1}$ Department of Dermatology, University of Heidelberg, Heidelberg, Germany \\ ${ }^{2}$ SWS Study Centers \\ (University of Heidelberg, Department of Dermatology; Medical practices: Dres. Brust/Schuster, Mannheim, \\ Dres. Mostaf/Procaccianti/Zutavern-Bechtold, Karlsruhe; Dres. Rump/Usadel, Freiburg)
}

\begin{abstract}
Background: There is an unmet medical need for simplified antiretroviral therapy regimens to improve patient's compliance and quality of life. The purpose of this study was to evaluate the efficacy and safety of a once-daily regimen with Tenofovir (TDF), Emtricitabine (FTC) and Nevirapine (NVP) for adult patients with HIV-1 infection.

Methods: 70 patients were enrolled in a prospective, multicenter, non-randomized, single arm, open-label cohort study. Patients were either naïve or had problems with their current ART and needed to be changed to another regimen. Daily drug dosage was $300 \mathrm{mg}$ Tenofovir, 200mg Emtricitabine and $400 \mathrm{mg}$ Nevirapine once daily. Follow-up was performed over 72 weeks.

Results: After 72 weeks, the regimen was still continued by 52 patients $(74,3 \%)$. Of these, 44 patients $(84,6 \%)$ had a viral load below detection limit. The median viral load had decreased by $2,5 \log$ and the median CD4 cell count had increased by $44,8 \%$. Most side-effects occurred at an early stage during the study. Resistances were rare (only two resistances were considered as newly developed) and occurred rather late during the study.

Conclusion: A once-daily regimen of Tenofovir, Emtricitabine and Nevirapine is an attractive treatment option since it is safe, effective, and well tolerated.
\end{abstract}

Key words: Nevirapine, Tenofovir, Emtricitabine, ART, treatment efficacy, once-daily

\section{INTRODUCTION}

A massive progress in the treatment of HIV infected patients has occurred in the past decade. With the availability of an increasing number of potent antiretroviral drugs and new treatment groups an effective anti-retroviral therapy (ART) has been established. Today longterm survival under ART with high levels of CD4 $\mathrm{T}$ cells seems a realistic aim. However, now that there are potent anti-retroviral therapies available the focus of attention has shifted towards improvement of quality of life. There is still an unmet medical need for treatment simplification in HIV therapy: Convenient and easy therapy regimens are not only needed to improve quality of life, but also to maintain patient compliance, which has been shown to be a major factor for long term therapeutic success. However, for any new regimens it is necessary to prove their efficacy and safety first as measured by reduction of viral load, improvement of CD4 $\mathrm{T}$ cell count and occurrence of side-effects.

We therefore investigated the long-term efficacy and tolerability of a simplified therapy regimen with Tenofovir $300 \mathrm{mg}$ and Emtricitabine $200 \mathrm{mg}$ plus Nevirapine $400 \mathrm{mg}$ at a once-daily dosage to asses, if this facilitated therapy scheme is appropriate to provide reliable therapeutic effects and a tolerable safety profile.

\section{MeTHODS \\ Patients}

70 patients were enrolled in a multicenter, prospective, non-randomized, single arm, open-label cohort study at four outpatient centers in southern Germany and follow-up was performed for 72 weeks. Only patients above 18 years of age with documented HIV1-infection who were naïve for antiretroviral therapy or experiencing side effects with their current ART regimen were included in the study. Patients showing NNRTI resistance or K65R, M41L or L210W mutation were excluded from the study. Patients gave their written informed consent and the study was conducted in accordance with the declaration of Helsinki.

\section{Study Protocol and Laboratory Testing}

At baseline visit patients were started with Tenofovir $300 \mathrm{mg}$, Emtricitabine 200mg and Nevirapine $400 \mathrm{mg}$ as once-daily medication. Study visits were performed at weeks 0, 2, 4, 6, 12, 24, 36, 48, 60 and 72. Viral load, CD 4 and CD $8 \mathrm{~T}$ cell counts as well as creatinin, GOT and GPT serum concentrations were obtained at each visit. Plasma HIV RNA levels were measured using PCR with a lower limit of quantification of 50 
copies/ml. CD4 T cell count was measured by flow cytometry. Viral load modification and changes in CD4 T cell count were considered as primary outcome measures. Discontinuation and failure of follow-up were considered as treatment failure.

\section{STATISTICS}

Data was checked for Gaussian distribution. Viral load data was found not to follow a Gaussian distribution, therefore a Kruskal-Wallis test was used for statistical analysis. As post test Dunn`s test was used. Data of CD4 $\mathrm{T}$ cell counts followed a Gaussian distribution, and consecutively a one-way ANOVA was performed, followed by Bonferroni`s test as post test. In all post tests data was compared to week 0 .

Table 1. Baseline patient characteristics.

\begin{tabular}{ll}
\hline Total patients & 70 \\
Male & 53 \\
Female & 17 \\
& \\
Patients with VL $>100.000$ & 12 \\
Patients with VL <50 & 27 \\
& 41,7 (range 20-72 years) \\
Mean age (years) & 32 \\
ART naïve & 38 \\
ART experienced & \\
& 76375 \\
Mean viral load (copies/ml) & 161789 \\
ART naïve & 4448 \\
ART experienced & \\
& 377 \\
Mean CD4 count (per $\mu \mathrm{l})$ & 255 \\
ART naïve & 480 \\
ART experienced &
\end{tabular}

\section{RESULTS}

After 72 weeks, the regimen was still continued by 52 patients $(74,3 \%) .5$ patients were lost to follow-up and 14 patients (including one patient lost to follow-up later on) had to be switched to another regimen because of liver toxicity ( 5 patients), virologic failure (4 patients) elevated serum CK (1 patient) or other causes (4 patients).

Of the patients continuing the original regimen until week 72,44 patients $(84,6 \%)$ had a viral load below detection limit at that time point; if split up into therapy naive and experienced patients, $21(91,3 \%)$ of the naive patients and $23(82,1 \%)$ of the experienced patients showed a viral load below detection limit. The median viral load had decreased by 2,5 log (2,7 log in the therapy naïve group and 1,5 log in the therapy experienced group). The median CD4 $\mathrm{T}$ cell count had increased by $44,8 \%$ (from 377,2 cells/ $\mu$ l to 546,3 cells $/ \mu \mathrm{l}$ ); by $86,8 \%$ in the therapy naïve group (from 255 cells $/ \mu$ lo 477 cells $/ \mu \mathrm{l}$ ) and by $25,7 \%$ in the therapy experienced group (from 479,8 cells/ $\mu$ lo 603,0 cells $/ \mu \mathrm{l})$.

Of the four patients, which were switched to another regimen because of virologic failure, two patients were switched at week 12 because they did not show
Viral load all patients

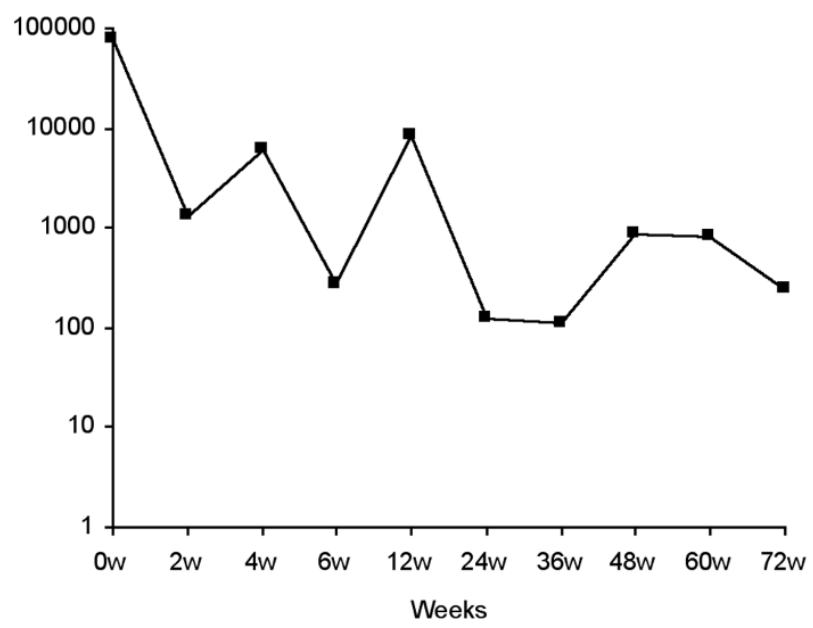

Fig. 1. Viral load all patients (during regimen intake).

Viral load therapy naive patients

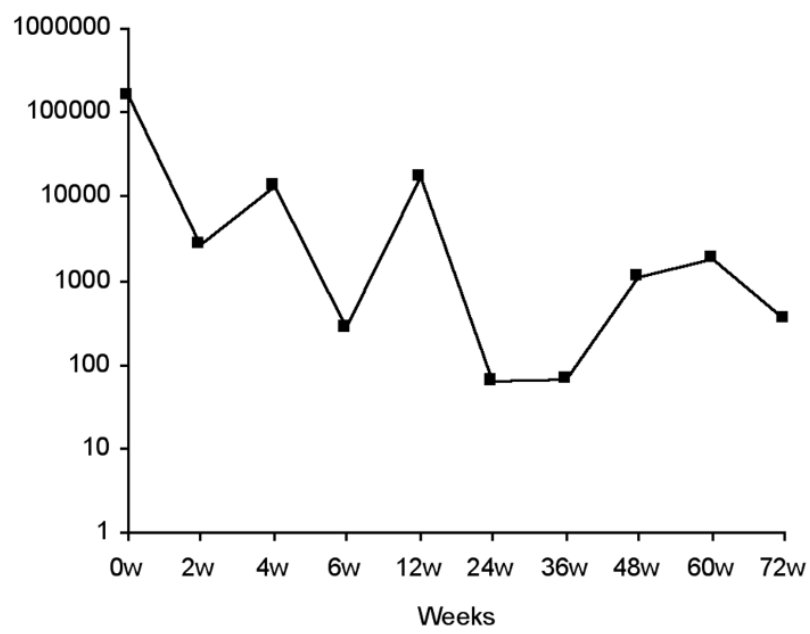

Fig. 2. Viral load therapy naïve patients.

Viral load therapy experienced patients

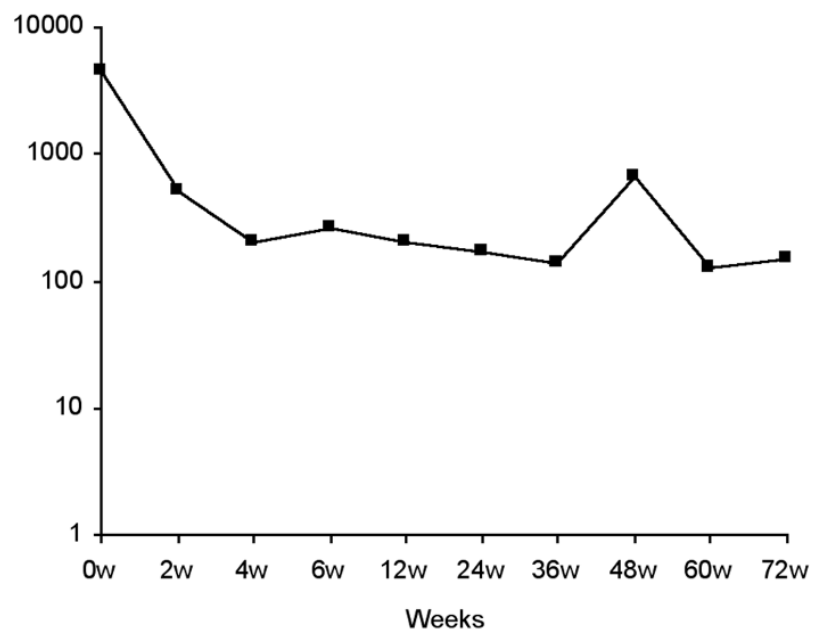

Fig. 3. Viral load therapy experienced patients. 
CD4 count all patients

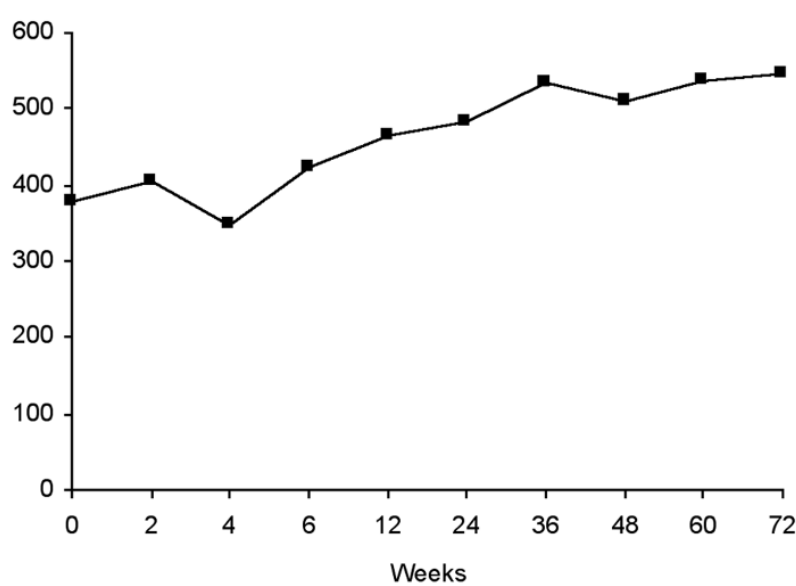

Fig. 4. CD4 count all patients (during regimen intake).

CD4 count therapy naive patients

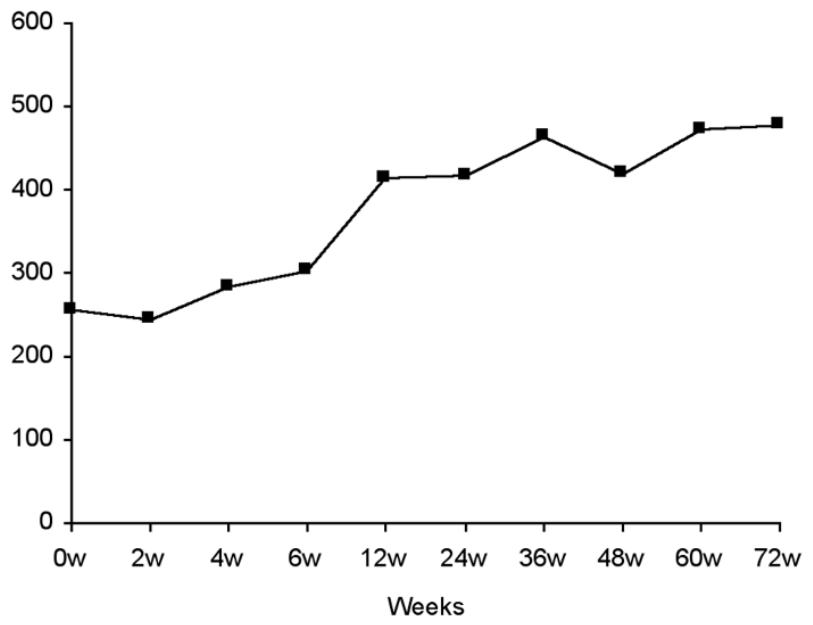

Fig. 5. CD4 count therapy naïve patients.

CD4 count therapy experienced patients

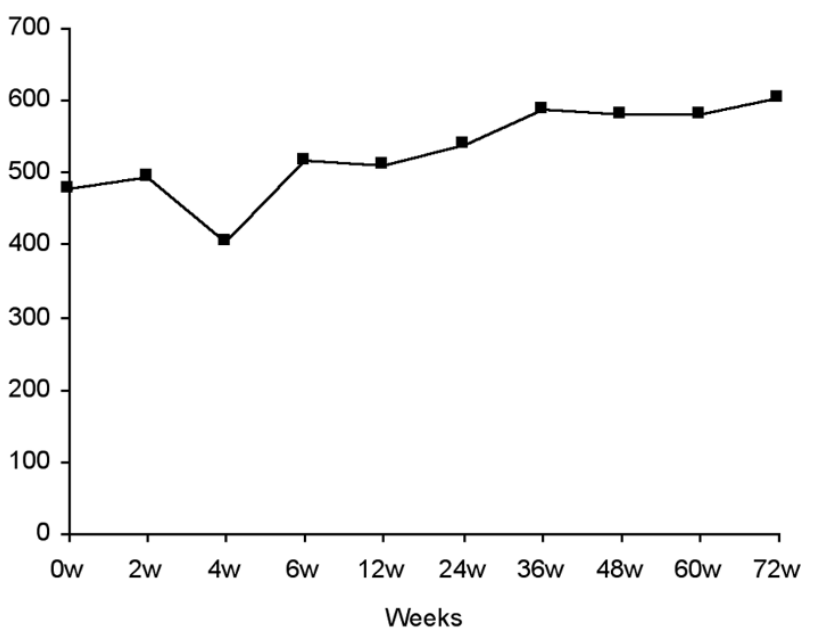

Fig. 6. CD4 count therapy experienced patients. sufficient virologic response until this time point, strongly suggesting baseline resistance, which had not been detected during screening. The other two patients had to be switched at a rather late time point (after 48 weeks) after they had shown reduction of viral load earlier during the treatment, suggesting the development of new resistance(s).

Occurrence of side effects however developed rather early: 3 male and 2 female patients had to be discontinued because of liver toxicity (after 2, 2, 4, 12, and 24 weeks). Both female patients had baseline CD4 T cell counts above 250 cells $/ \mu \mathrm{l}(257$ and 412 cells $/ \mu \mathrm{l})$ but all 3 male patients were below 400 cells/ $\mu$ l at the beginning of the therapy (250, 231 and 296 cells/ $\mu \mathrm{l})$. One patient was discontinued because of a massively elevated serum $\mathrm{CK}$ at week 2 .

\section{DisCUSSION}

There is increasing evidence that the complexity of a regimen is strongly related to patients' compliance [1, $2,3,4]$. This correlation affects a wide population of HIV positive patients, since it has been shown to be independent of demographic (race, ethnicity, education), clinical (most recent CD4 count/ HIV RNA level, depression) or behavioural (drug use history) influences [5].

In order to improve patients' compliance and thereby increase long time therapy success in a big group of HIV positive patients new simplified once-daily regimens are needed.

Non-nucleoside reverse transcriptase inhibitors (NNRTIs) seem to be the ideal drugs for simplified ART regimens because of their extremely long halflife which assures high plasma levels over a long time and thus sustained efficacy in inhibition of viral reproduction even during long treatment intervals.

Of the currently licensed NNRTIs only Efavirenz has been approved for once-daily administration. There is an ongoing discussion of whether Nevirapine might be suitable for once-daily regimens as well. It has been shown that Nevirapine achieves high steadystate plasma concentrations relative to the concentration required to inhibit $50 \%$ viral replication in vitro (IC(50)) and that the daily exposure to nevirapine, as measured by the plasma concentration over 24 hours (area under the curve, AUC24), as well as half-life and time to maximal plasma concentration were not significantly different between the $400 \mathrm{mg}$ once-daily and $200 \mathrm{mg}$ twice-daily dose regimen. However, in the once-daily group there were higher maximal and lower minimal plasma concentrations $[6,7]$. These findings were consistent with the data acquired in the $2 \mathrm{NN}$ study [8], which further analyzed the clinical implications of these differences in plasma levels. After 48 weeks no differences in treatment failures were found comparing the Nevirapine 400mg once-daily and $200 \mathrm{mg}$ twice-daily regimen [9]. In addition, no statistically significant differences in treatment failure were found comparing Efavirenz and Nevirapine as onceor twice-daily regimen. Also, no significant differences in the occurrence of grade 3 and 4 events were found between these three groups.

Even though these data suggest that Nevirapine ap- 
pears to be suitable for once-daily regimens, there is still only few data available about the use of Nevirapine in this context. Nevertheless there seems to be a need for a longer follow-up to actually determine the continuous efficacy of a regimen [10]. Very little data is available about the fixed combination of Nevirapine, Tenofovir and Emtricitabine at a once-daily dosage.

We therefore investigated the simplified regimen of Nevirapine 400mg, Tenofovir 300mg and Emtricitabine $200 \mathrm{mg}$ (each taken once daily) over 72 weeks.

We found that in the long-term assessment the regimen was effective and well tolerated. Side-effects were rare and occurred at a rather early stage: Only two patients $(2,9 \%)$ had to be discontinued from the regimen because of side effects after week 4. However, treatment was interrupted in eight patients $(11,4 \%)$ because of side-effects in the first four weeks. When splitting up patients with side-effects, we found gender-specific differences with a higher incidence in the female study population. Thus, these results emphasise the need for more gender specific investigations of effectiveness and safety in certain HIV therapy regimens.

Furthermore, only two patients $(2,9 \%)$ were considered of having developed new treatment-limiting resistances during 72 weeks. These findings are in contrast with the data of the DAUFIN study (zidovudine/lamivudine $300 \mathrm{mg} / 150 \mathrm{mg}$ plus nevirapine 200 $\mathrm{mg}$ twice daily versus lamivudine $300 \mathrm{mg}$, tenofovir $245 \mathrm{mg}$ and nevirapine $400 \mathrm{mg}$ once daily) which was stopped after early virologic failure in the once-daily versus twice-daily group. However, different backbones were used in both groups and the baseline characteristics in the once-daily group indicated a significantly higher median viral load and significantly lowed CD4 T cell count [11], thus explanatory power of the study findings must certainly be challenged.

Another study revealed that the once-daily dosage of Nevirapine (used with a fixed backbone of Lamivudine and Stavudine) performed even better than the twice-daily dosage in preventing treatment failure [12]. These data are more consistent with our findings of only little resistance development during the once-daily dosage of Nevirapine. Nevertheless, further research is needed to investigate prevention of early treatment failure to increase therapy efficacy and safety.

\section{CONCLUSION}

Nevirapine once-daily, when used with a fixed backbone of Tenofovir and Emtricitabine, is a very safe and effective regimen, especially after the initiation phase.

\section{REFERENCES}

1. Gifford AL, Bormann JE, Shivley MJ, et al. Predictors of selfreported adherence and plasma HIV concentrations in patients on multidrug antiretroviral regimens. J Acquir Immune Defic Syndr. 2000;23: 386-95

2. Ammassari A, Murri R, Pezzotti P, et al. Self-reported symptoms and medication side effects influence adherence to highly active antiretroviral therapy in persons with HIV infection. J Acquir Immune Defic Syndr. 2001; 28: 445-9.

3. Trotta MP, Ammassari A, Melzi S, et al. Treatment-related factors and highly active antiretroviral therapy adherence. J Acquir Immune Defic Syndr. 2002; 15: 31(suppl 3), S128-131.

4. Portsmouth SD, Osorio J, McCormick K, Gazzard BG, Moyle GJ. Better maintained adherence on switching from twice-daily to once-daily therapy for HIV: a 24week randomized trial of treatment simplification using stavudine prolonged-release capsules. HIV Med. 2005; 5:185-190

5. Stone VE, Hogan JW, Schuman P, et al. Antiretroviral regimen complexity, self-reported adherence, and HIV patients' understanding of their regimens: Survey of women in the HER study. J Acquir Immune Defic Syndr. 2001; 28: 124-131.

6. Cooper CL, van Heeswijk RP. Once-daily nevirapine dosing: a pharmacokinetics, efficacy and safety review. HIV Med. 2007; 8: 1-7.

7. Van Heeswijk RP, Veldkamp AI, Mulder JW, Meenhorst PL, Wit FWNM, Lange JMA, Danner SA, Foudraine NA, Kwakkelstein MO, Reiss P, Beijnen JH, Hoetelmans RMW. AIDS. 2000; 14: 8,F77-F82.

8. Kappelhoff BS, Huitema AD, van Leth F, Robinson PA, MacGregor TR, Lange JM, Beijnen JH; 2NN Study Group. Pharmacokinetics of nevirapine: once-daily versus twice-daily dosing in the 2NN study. HIV Clin Trials. 2005; 6: 254-261.

9. Van Leth F, Phanuphak P, Ruxrungtham K, Baraldi E, Miller S, Gazzard B, Cahn P, Lalloo UG, van der Westhuizen IP, Malan DR, Johnson MA, Santos BR, Mulcahy F, Wood R, Levi GC, Reboredo G, Squires K, Cassetti I, Petit D, Raffi F, Katlama C, Murphy RL, Horban A, Dam JP, Hassink E, van Leeuwen R, Robinson P, Wit FW, Lange JM; 2NN Study team. Lancet. 2004; 17;363(9417): 1253-63

10. Keiser P, Nassar N, Yazdani B, Armas L, Moreno S. HIV Clin. Trials. 2003; 4(5): 358-360.

11. Clotet B. Once-daily dosing of nevirapine in HAART. J Antimicrob Chemother. 2008; 61: 13-16.

12. Siegfried NL, Van Deventer PJ, Mahomed FA, Rutherford GW. Stavudine, lamivudine and nevirapine combination therapy for treatment of HIV infection and AIDS in adults. Cochrane Database Syst Rev. 2006 Apr 19;(2): CD004535

Received: May 5, 2009 / Accepted: October 20, 2009

\section{Address for correspondence:}

Tanja Weberschock

Universitäts-Hautklinik Heidelberg

Immunologische Ambulanz

Voßstr. 2

69115 Heidelberg

Germany

Phone: +49(0)6221/567011

E-mail: tanja.sehr@med.uni-heidelberg.de 